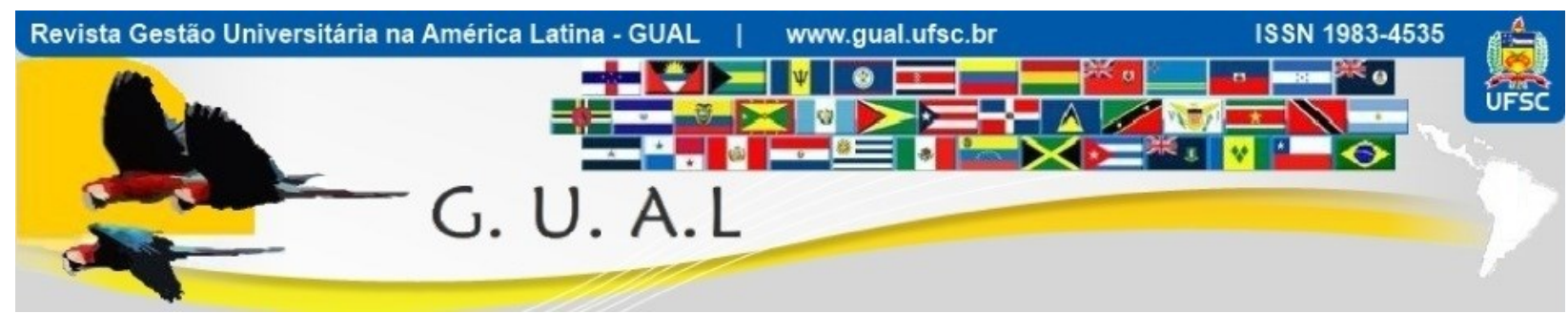

DOI: http://dx.doi.org/10.5007/1983-4535.2016v9n4p189

\title{
INCUBADORAS TECNÓLOGICAS DE COOPERATIVAS POPULARES: ATUANDO A PARTIR DA EXTENSÃO UNIVERSITÁRIA
}

\section{INCUBATORS TECHNOLOGICAL COOPERATIVE: ACTING FROM UNIVERSITY EXTENSION}

Louise de Lira Roedel Botelho, Doutora Universidade Federal da Fronteira Sul - UFFS louisebotelho@uffs.edu.br

Djéssica Follmann de Lima, Graduada Universidade Federal da Fronteira Sul - UFFS djessy_fl@yahoo.com.br

Júlia Catiane Arenhart Braun, Graduada Universidade Federal da Fronteira Sul - UFFS julia_catiane@yahoo.com.br

Artur Filipe Ewald Wuerges, Mestre Universidade Federal de Santa Catarina - UFSC artur.wuerges@uffs.edu.br

Fernando Alvaro Ostuni Gauthier, Doutor Universidade Federal de Santa Catarina - UFSC gauthier@egc.ufsc.br

Sandra Vidal Nogueira, Doutora Universidade Federal da Fronteira Sul - UFFS sandra.nogueira@uffs.edu.br

Agradecimento especial ao CNPq, agente financiador desta pesquisa.

Recebido em 04/dezembro/2015

Aprovado em 14/outubro/2016

Sistema de Avaliação: Double Blind Review 


\title{
RESUMO
}

O presente trabalho é um resultado de uma pesquisa sobre o mapeamento das Incubadoras Tecnossociais de Cooperativas Populares (ITCP) realizada no sul do Brasil, cujo objetivo é analisar a situação atual destas. A metodologia utilizada para a realização desta pesquisa foi o método da revisão bibliográfica integrativa seguida pelos dados do mapeamento das incubadoras, construção e qualificação de um questionário quantitativo. O questionário foi aplicado em incubadoras da região sul do Brasil onde foram analisados e processadas as respostas das ITCPs do Rio Grande do Sul em uma Planilha Calc do software livre da LibreOffice. Com a pesquisa, observou-se que os empreendimentos incubados nas ITCPs enfrentam dificuldades no início da incubação, principalmente quanto aos custos de financiamento. Constatou-se também que muitos empreendimentos incubados não possuem legalização de suas atividades. Pôde-se observar que as principais linha de atuação dos empreendimentos incubados são a Economia Solidária, Cooperativas e Agricultura Familiar. Os dados obtidos com a presente pesquisa são de grande relevância para avaliar a situação atual das ITCPs do Rio Grande do Sul, porém é necessário um aprofundamento em futuras pesquisas para entender qualitativamente a situação e como esta pode ser melhorada.

Palavras-chaves: Incubadoras. Extensão universitária. Revisão integrativa.

\begin{abstract}
This work is a result of research on the mapping of techno-social Incubators Cooperatives (ITCP) held in southern Brazil, which aims to analyze the current situation of these. The methodology used for this research was the method of integrative literature review followed by mapping data from incubators, construction and qualification of a quantitative questionnaire. The questionnaire was applied in incubators of southern Brazil where they were analyzed and processed the responses of ITCPs of Rio Grande do Sul in a Calc spreadsheet free of LibreOffice software. Through research, it was observed that the enterprises incubated in ITCPs face difficulties at the beginning of incubation, especially regarding the financing costs. It was also found that many enterprises do not have incubated legalization of their activities. It was observed that the main line of action of the incubated enterprises are the Solidarity Economy, Cooperatives and Family Agriculture. The data obtained from this research are of great importance to assess the current status of the Rio Grande do Sul ITCPs, but requires a deepening in future research to qualitatively understand the situation and how it can be improved.
\end{abstract}

Key-Words: Incubators. University extension. Integrative review. 


\section{INTRODUÇÃO}

Este artigo apresenta o resultado de uma pesquisa sobre o mapeamento realizado em Incubadoras Tecnológicas de Cooperativas Populares (ITCPs) no sul do Brasil. As incubadoras em análise, estão vinculadas a REDE de ITCPs.

O cenário do desenvolvimento econômico mundial encontra-se em um processo de grandes transformações nas últimas décadas devido a diversos fatores, como a globalização, emergência de novos mercados, avanços tecnológicos e da informação, e uma demanda crescente por inovações, causando um forte impacto socioeconômico e provocando alterações nos mais diversos níveis das organizações (ENGELMAM e FRACASSO, 2013).

$\mathrm{Na}$ experiência brasileira e de outros países, as incubadoras tecnológicas representam um esforço para formação desse ambiente favorável (ENGELMAM e FRACASSO, 2013). As incubadoras são espaços compartilhados que proporcionam aos novos negócios, espaço físico e recursos organizacionais, monitoramento e ajuda empresarial (MEDEIROS, 1997).

Este trabalho tem por objetivo verificar a atuação das Incubadoras Tecnossociais de Cooperativas Populares (ITCPs) no Estado do Rio Grande do Sul. A verificação é feita para ver o desenvolvimento e construção das ITCPs nos últimos anos, servindo como forma de construção de um panorama conceitual sobre a atuação destas incubadoras no Estado.

O mapeamento das incubadoras, presentes na região sul do Brasil, torna-se importante, para o reconhecimento das atividades desenvolvidas, bem como, o número de incubados, tempo de atuação e por quem suas equipes são formadas.

A ampliação do leque de conhecimentos, sobre as incubadoras é vista como uma clara oportunidade a ser explorada, com benefícios potenciais, tanto para os bancos de dados, como também, para as demais incubadoras presentes em outras regiões do país, garantindo assim, a melhor visualização das práticas que obtiveram sucesso e dos desafios enfrentados no âmbito organizacional (JAYO e DINIZ, 2013).

Este artigo está divido em três seções, essas seções abordam inicialmente o que é a extensão universitária, qual a sua origem e a importância desta na Universidade. Em seguida, é realizada uma contextualização sobre as ITCPs, como atuam e qual os financiadores e apoiadores. Para finalizar, foi realizada uma análise dos dados quantitativos e quais os pontos em comum entre as incubadoras do Rio Grande do Sul. 


\section{O QUE É EXTENSÃO UNIVERSITÁRIA?}

Muitos autores apontam que o início da extensão universitária ocorreu com as universidades populares europeias dos últimos séculos, que objetivavam disseminar os conhecimentos técnicos com a população. Na Inglaterra também surgiu o pensamento que a universidade precisava contribuir aos setores populares com um maior conhecimento, a partir disto começou-se a estudar como seria possível chegar a estas parcelas da população, e a universidade contribuiria com este conhecimento através da extensão universitária. Mas foi a partir das experiências americanas que surgiram duas novas visões diferenciadas das europeias, a visão cooperativa ou rural e a universitária em geral, estas que tinham como ideia principal a prestação de serviços (MELO NETO, 2002).

$\mathrm{Na}$ América Latina, a extensão universitária surgiu a partir do documento de Córdoba, em 1918, onde estudantes realizaram um manifesto criticando a falta de espírito científico da universidade, reivindicando maior acesso à universidade, atenção da universidade para as questões sociais e para a situação de dominação colonial que os latinos viviam. A partir deste manifesto os estudantes tiveram a oportunidade de se familiarizar com os problemas da realidade social e ter um contato direto com as populações e, consequentemente, contribuir com a qualidade da educação (GURGEL, 1986).

Souza (2005) afirma que a universidade popular surgiu no Brasil através da instalação da Universidade Livre de São Paulo, no ano de 1912, e recebeu influências do médico Eduardo Augusto Guimarães. Esta universidade trazia o aparecimento da universidade popular junto do ensino superior e definiu a primeira proposta de extensão no país, os cursos de extensão, prática difundida nacionalmente. Como a universidade oferecia cursos abertos ao povo que não despertavam o seu interesse, ela foi fechada. Outras tentativas de afirmação da atuação da atuação da universidade junto às populações feitas na Universidade Popular do Maranhão, Rio de Janeiro, Universidade Livre do Amazonas e Universidade Livre do Paraná.

A partir da década de 30 foi retomada no país a ideia de universidade popular e ocorreu então uma grande movimentação em experiências de práticas educativas de extensão, como salas de leituras, experiências de rádio e difusão, difusão cultural, cursos de conferência aberta para discussão e solução de problemas sociais. A extensão universitária, a partir disto, passa a fazer uma troca entre os saberes populares e a universidade, ocorrendo então a transformação da sociedade e a relação desta com o ensino e pesquisa (SERRANO, s./a./). 
Para a superação da extensão universitária como uma prestação de serviços, é dada uma ênfase na extensão como a relação da teoria e prática, buscando a troca de saberes entre a universidade e sociedade. Esta concepção afasta a ideia da extensão como uma atividade menor e passa a ser uma parte integrante da dinâmica pedagógica curricular no processo de formação e produção de conhecimento envolvendo professores e alunos e possibilitando a formação crítica. Com esta postura, é possível entender as expectativas da sociedade e analisar o contexto em que estão inseridas para que ambos, universidade e sociedade, consigam obter a relação de reciprocidade mutuamente transformadora entre elas (JEZINE, 2004).

$\mathrm{Na}$ universidade, a extensão como função acadêmica, deve se integrar ao ensino/pesquisa para incorporar a extensão universitária às práticas de ensino e pesquisa. $\mathrm{O}$ princípio da indissociabilidade das atividades de ensino, pesquisa e extensão é fundamental na formação acadêmica, pois a relação entre esses três pilares, quando bem articulados, traz mudanças significativas nos processos de ensino e de aprendizagem, melhorando a formação dos estudantes e trazendo significativas contribuições aos professores que repassam este conhecimento. A pesquisa e a extensão, integrados ao ensino, com a universidade e com a sociedade, possibilita a melhoria da relação da teoria e prática, compartilhando o saber acadêmico com a sociedade e recebendo-o de volta, testado e reelaborado (DIAS, 2012).

Segundo Nogueira (2013), a universidade tem a extensão como um instrumento para cumprir a sua função social, através desta é possível democratizar o conhecimento produzido e ensinado na universidade e possibilitar que a universidade atenda às demandas mais urgentes da população, promovendo assim, a reconstrução de uma sociedade mais justa.

Com os avanços do Ensino Superior em relação à extensão universitária, uma de suas tendências de aplicabilidade é a instalação de ITCPs nas Universidades, estas que são uma unidade acadêmica interdisciplinar entre ensino, pesquisa e extensão, e que são instrumentos para possibilitar a troca de saberes populares com os saberes acadêmicos.

O papel das ITCPs é atuar na geração e disseminação do conhecimento entre a universidade e grupos que se encontram a margem do processo de desenvolvimento econômico no Brasil (SILVA et al., 2009). Tudo isso, com base na formação de políticas e projetos de extensão, os quais tendem a repercutir positivamente nas vidas daqueles que puderam ter acesso a este. 


\section{SURGIMENTO DAS ITCPs: O QUE SÃO, E QUAL O SEU PAPEL?}

A gênese das incubadoras está pautada no contexto organizacional americano, isso em virtude das mudanças sociais ocorridas no início do século passado e também aos períodos de dificuldade financeira que as organizações americanas enfrentavam. Desse modo, as incubadoras foram criadas como mecanismos para a reversão de determinadas situações econômicas.

A definição de incubadora e seu papel na sociedade é essencial, para o entendimento das características que constituem as mesmas. Fonseca e Kruglianskas (2000) argumentam que a essência das incubadoras, está voltada para a impulsão de novos negócios.

No Brasil, as incubadoras surgiram através da replicação das experiências americanas, contudo, sua atuação se volta para a construção de novos conhecimentos, incentivando a produção de tecnologias de ponta, por isso, em sua maioria, encontram-se vinculadas a instituição de ensino (ANPROTEC, 2003).

No Brasil, o movimento das incubadoras de empresas iniciou na década de 1980. Essa década foi marcada por uma economia estagnada e dos movimentos sociais. A crise da dívida externa atingiu o país tão duramente quanto ao resto da América Latina. A ditadura militar transformou-se em um movimento pela democracia, mas também pela transformação social. A redemocratização veio em 1985 e, com isso, em 1988, foi aprovada uma constituição de viés social-democrata (GUIMARÃES, 2000).

As ITCPs surgem a partir do apoio do Conselho Nacional de Desenvolvimento Científico e Tecnológico - CNPq e a adesão de agências como a Financiadora de Estudos e Projetos - FINEP e a Organização dos Estados Americanos - OEA, no plano supranacional. Esta organização se baseia em quatro pilares para alcançar seus objetivos: democracia, direitos humanos, segurança e desenvolvimento.

O projeto das Incubadoras Tecnológicas de Cooperativas Populares (ITCPs) teve inspiração no movimento em prol da cidadania contra a fome e a miséria, onde professores da Fundação Oswaldo Cruz (Fiocruz) sensibilizados com o contexto social da favela vizinha, identificaram que o principal fator desta situação era o desemprego desta população. Em vista disto a Fiocruz, em parceria com a Universidade de Santa Maria/RS, fundou uma cooperativa de trabalho, Cooperativa de Manguinhos, formado pelos moradores da região, que prestava serviços a própria Fiocruz (SOUZA et al., 2003). 
A partir desta ação criou-se, em 1995, a primeira Incubadora Universitária de Cooperativas Populares, a ITCP/COOP /UFRJ, através da Coordenação de Programas de PósGraduação em Engenharia da Universidade Federal do Rio de Janeiro cujo objetivo inicial foi estabelecer um contato com comunidades das favelas interessadas na formação de cooperativas de trabalho (SOUZA et al., 2003; RELATÓRIO DE TECNOLOGIA SOCIAL, 2007, p.8). A partir desta iniciativa e sua repercussão, outros grupos, em outras universidades, buscaram informações e fontes para a construção de projetos similares, e algumas universidades também iniciaram a construção de outras ITCP's. A inserção das Incubadoras nas Instituições de Ensino Superior têm contribuído muito para a construção de uma nova cultura do trabalho individual para o trabalho consciente e transformador (IADH, 2011, p.3).

A partir dos anos de 2000, observou-se o crescimento de incubadoras sociais em universidades brasileiras, tudo isso em virtude dos programas de fomento a economia solidária promovidos pelo governo.

Para isso, o Ministério do Trabalho e Emprego (MTE), responsável por políticas e diretrizes para a geração de emprego e apoio ao trabalho, criou políticas públicas que beneficiassem a criação e o funcionamento das ITCPs no país. Em 2003, o governo Lula foi responsável pela criação da Secretaria Nacional de Economia Solidária (SENAES). Tem-se também o Programa Nacional de Incubadoras Tecnológicas de Cooperativas Populares (PRONINC), programa de fomento a extensão vinculado à FINEP, à FBB e ao COEP, que foi criado em 1998, que em 2003 com a criação da SENAES/MTE, o PRONINC passou a ser coordenado por essa Secretaria, a articulação com o MEC, MDS, MS, BB, além dos órgãos que originalmente haviam apoiado o programa e permitiu que o mesmo fosse reiniciado (MTE/SENAES, 2015).

Em relação ao Programa Nacional de Incubadoras de Cooperativas Populares (PRONINC), temos o Decreto 7.357, de 17 de novembro de 2010. Esse decreto deixa claro que o PRONINC implementa-se de forma integrada pelos diversos órgãos do Governo Federal, e tem como finalidade apoiar a consolidação e ampliar as incubadoras de empreendimentos econômicos solidários, de modo a favorecer a criação e o acompanhamento de novos empreendimentos ou fortalecer empreendimentos já criados, por meio da oferta de qualificação e assistência técnica durante o período de incubação.

Para Lalkaka e Bishop Jr. (1997) incubadora é a denominação utilizada para definir o espaço institucional para apoiar a transformação de empresários potenciais em empresas 
crescentes e lucrativas. As incubadoras sociais são meios utilizados para assessorar empreendimentos vindos de projetos sociais. São um forte canal entre a universidade e a comunidade, sendo assim, formulam ideias de empreendimentos sustentável a comunidade e auxiliam o conhecimento acadêmico (BEZERRA et al., 2013). Seu principal objetivo, é interagir o meio universitário e os grupos de trabalhadores, que tentam empreender economicamente e de forma coletiva. Isso é feito através de um processo intenso de troca de conhecimentos práticos e teóricos e de uma construção compartilhada de novos conhecimentos, entre a incubadora e os grupos de trabalhadores associados incubados. Uma incubadora social tem como objetivo apoiar e incentivar entidades, organizações sociais e lideranças comunitárias e criar empreendimentos e projetos inovadores nas áreas sociais, culturais, econômicas e ambientais (MORETTO NETO, GARRIDO e JUSTEN, 2011).

As ITCPs possuem uma política de ação voltada para a promoção do desenvolvimento local, articulada com a atuação de outros atores da sociedade civil, levando em consideração as vocações, as potencialidades locais e os interesses da comunidade. São um ambiente propício para estimular o desenvolvimento de pequenos empreendimentos populares (UFPA, s./a./).

Atualmente no Brasil, as ITCPs se encontram vinculadas a dois grandes grupos de articuladores, a Rede Universitária de Incubadoras Tecnológicas de Cooperativas Populares (Rede de ITCPs) e a Rede Unitrabalho. Essas redes, que apoiam as incubadoras de cooperativas populares e ajudam a desenvolver suas ações, visam possibilitar alternativas de trabalho e renda a indivíduos excluídos no mercado de trabalho. Até o ano de 2010 a Rede de ITCPs possuía 42 incubadoras filiadas e a Rede Unitrabalho contava com 92 universidades e instituições de ensino vinculadas em todo o país.

\section{METODOLOGIA}

Esta seção tem por finalidade apresentar o procedimento metodológico usado para a elaboração deste artigo. Deve-se levar em conta que este artigo é produto de uma pesquisa sobre o mapeamento das ITCPs do sul do país. A metodologia usada para que se pudesse chegar aos dados almejados, foi o método da revisão bibliográfica integrativa, como forma de se construir uma estrutura conceitual necessário, e assim, elaborar os produtos requeridos. Produtos esses que envolvem atividades de planejamento como, estudo teórico, pesquisa bibliográfica, mapeamento das incubadoras, construção e qualificação do questionário. $\mathrm{O}$ 
presente artigo apresenta o resultado de uma pesquisa sobre o mapeamento realizado em ITCPs no sul do Brasil, o qual foi aprovado pelo Comitê de Ética em Pesquisa com Seres Humanos - CEP/UFFS, com número do Protocolo CAAE 39607614.0.0000.5564.

Uma de suas fases, caracterizou-se pelo processo de coleta dos dados, através da aplicação de um questionário quantitativo estruturado ao universo das incubadoras sociais no sul do Brasil que estão vinculadas ao PRONIC (Programa Nacional de Incubadoras de Cooperativas). A aplicação do questionário, de acordo com o cronograma do projeto, deveria ter sido realizada nos meses de fevereiro, março e abril. Porém, em virtude da baixa participação e comprometimento das ITCPs, nossa coleta se estendeu até o mês de julho. Os dados foram processados em uma Planilha Calc do software livre da LibreOffice e os resultados são apresentados através de gráficos.

Segundo Terence e Escrivão Filho (2006), a pesquisa quantitativa permite a mensuração de opiniões, reações, hábitos e atitudes da parcela estudada, através da delimitação de uma amostra que o represente estatisticamente. Esta pesquisa segue um plano previamente estabelecido e busca enumerar e medir eventos utilizando instrumentos estatísticos para a análise de dados (NEVES, 1996).

Assim, o dilema de avaliação torna-se um fator que determina a qualidade das atividades desenvolvidas pelas incubadoras. Uma metodologia bem definida contribui para que não ocorram falhas e questionamentos sobre a validade de todo o processo. Desse modo, a metodologia de trabalho desenvolvida pelas incubadoras, também representa um desafio para o entendimento da realidade desses empreendimentos, permitindo uma oportunidade da construção de novos conhecimentos sobre a temática.

O questionário foi formulado com perguntas que favorecessem a identificação dos modelos de incubação, presentes nas incubadoras da região sul. No total foram selecionadas treze incubadoras vinculadas a instituições de ensino, em sua maioria universidades e que atuam na região, compreendendo os estados do Rio Grande do Sul, Paraná e Santa Catarina. Porém, a presente pesquisa teve como objetivo avaliar os questionários do estado do Rio Grande do Sul, sendo que apenas estes foram considerados para o trabalho.

Sendo assim, no total foram 7 incubadoras questionadas e a relação dos participantes da pesquisa encontra-se a seguir: 


\begin{tabular}{|c|c|}
\hline \multicolumn{2}{|c|}{ INCUBADORAS DA REGIÃO SUL DO BRASIL } \\
\hline Incubadoras & Instituição de Ensino Vinculada \\
\hline $\begin{array}{c}\text { Incubadora Tecnológica de Cooperativas Populares da } \\
\text { Universidade Federal do Rio Grande do Sul - ITCP } \\
\text { UFRGS }\end{array}$ & Universidade Federal do Rio Grande do Sul - UFRGS \\
\hline $\begin{array}{c}\text { ITECSOL - Incubadora de Tecnologia Social e } \\
\text { Economia Solidária }\end{array}$ & Universidade Regional do Noroeste do UNIJUI \\
\hline $\begin{array}{c}\text { Incubadora de Empreendimentos Solidários e } \\
\text { Tecnologia Social }\end{array}$ & $\begin{array}{l}\text { Pontifícia Universidade Católica do Rio Grande do Sul } \\
\qquad- \text { PUCRS }\end{array}$ \\
\hline $\begin{array}{l}\text { Incubadora de Empreendimentos Solidários do } \\
\text { Unilasalle }\end{array}$ & Centro Universitário La Salle - Canoas \\
\hline $\begin{array}{c}\text { Incubadora Tecnossocial de Cooperativas e } \\
\text { Empreendimentos Econômicos Solidários - ITCEES }\end{array}$ & $\begin{array}{l}\text { Universidade Federal da Fronteira Sul Campus Cerro } \\
\text { Largo - UFFS }\end{array}$ \\
\hline Incubadora Social da UFSM & Universidade Federal de Santa Maria - UFSM \\
\hline $\begin{array}{c}\text { Programa Tecnologias Sociais para Empreendimentos } \\
\text { Solidários - TECNOSOCIAIS }\end{array}$ & Universidade do Vale do Rio dos Sinos - UNISINOS \\
\hline
\end{tabular}

Quadro 1 Relação de incubadoras participantes da pesquisa no RS.

Fonte: Elaborada pelos autores.

O mapeamento das incubadoras, presentes na região sul do Brasil, torna-se importante, para o reconhecimento das atividades desenvolvidas, bem como, a identificação dos modelos de incubação propostos por essas incubadoras. A ampliação do leque de conhecimentos, sobre as incubadoras é vista como uma clara oportunidade a ser explorada, com benefícios potenciais, tanto para os bancos de dados, como também, para as demais incubadoras presentes em outras regiões no país, garantindo assim, a melhor visualização das práticas que obtiveram sucesso e dos desafios enfrentados no âmbito organizacional (JAYO e DINIZ, 2013). Do ponto de vista dos bancos de informações, o mapeamento das incubadoras significa a possibilidade da expansão dos conhecimentos proporcionados pelas mesmas. Pelo panorama social, o mapeamento permite a incorporação dos processos de incubação ofertados a diferentes contextos sociais, identificando as características dos grupos sociais beneficiados (IVATURY, 2006; KUMAR et al., 2006; LYMAN, IVATURY e STASCHEN, 2006; DINIZ, POZZEBON e JAYO, 2007).

Esta pesquisa colabora com o trabalho de Jayo e Diniz (2013), que procura contribuir com uma teoria descritiva, sobre um objeto anteriormente trabalhado pela literatura específica da área: a gestão das incubadoras, bem como, os modelos de incubação ofertados nas regiões sul do país.

Assim, as incubadoras carecem de mecanismos capazes de preservar os conhecimentos criados a partir de experiências passadas, mesmo quando o conhecimento já 
estabelecido se apresente como desafio no processo de compreensão da relevância desses empreendimentos. Desta forma, optou-se por pesquisar as incubadoras do Rio Grande do Sul, pois atualmente possui o maior número de ITCPs do sul do país.

\section{RESULTADOS}

As incubadoras do Rio Grande do Sul possuem o maior número de ITCPs do sul do país. Isso ocorre em virtude do grande número de empreendimentos na área da agricultura familiar. A relevância dessa pesquisa se ocupa em analisar a dinâmica de produção e circulação de conhecimento nas ITCPs do estado.

O presente trabalho tem como resultados os questionários que foram aplicados nas ITCPs no estado do Rio Grande do Sul com as incubadoras pertencentes à Rede de ITCPs, e os dados da pesquisa quantitativa estão apresentados a seguir.

Com os dados dos resultados dos questionários, pode se verificar que a média de tempo de atuação das ITCPs do Rio Grande do Sul é de 7 anos e que a média de participantes é de 10 pessoas por incubadora, sendo estes professores, bolsistas e técnicos.

Observa-se que a maioria das ITCPs do Rio Grande do Sul incubam 6 ou mais empreendimentos (57\%), 29\% incubam de 1 a 3 empreendimentos e $14 \%$, de 4 a 5 empreendimentos (Figura 1).

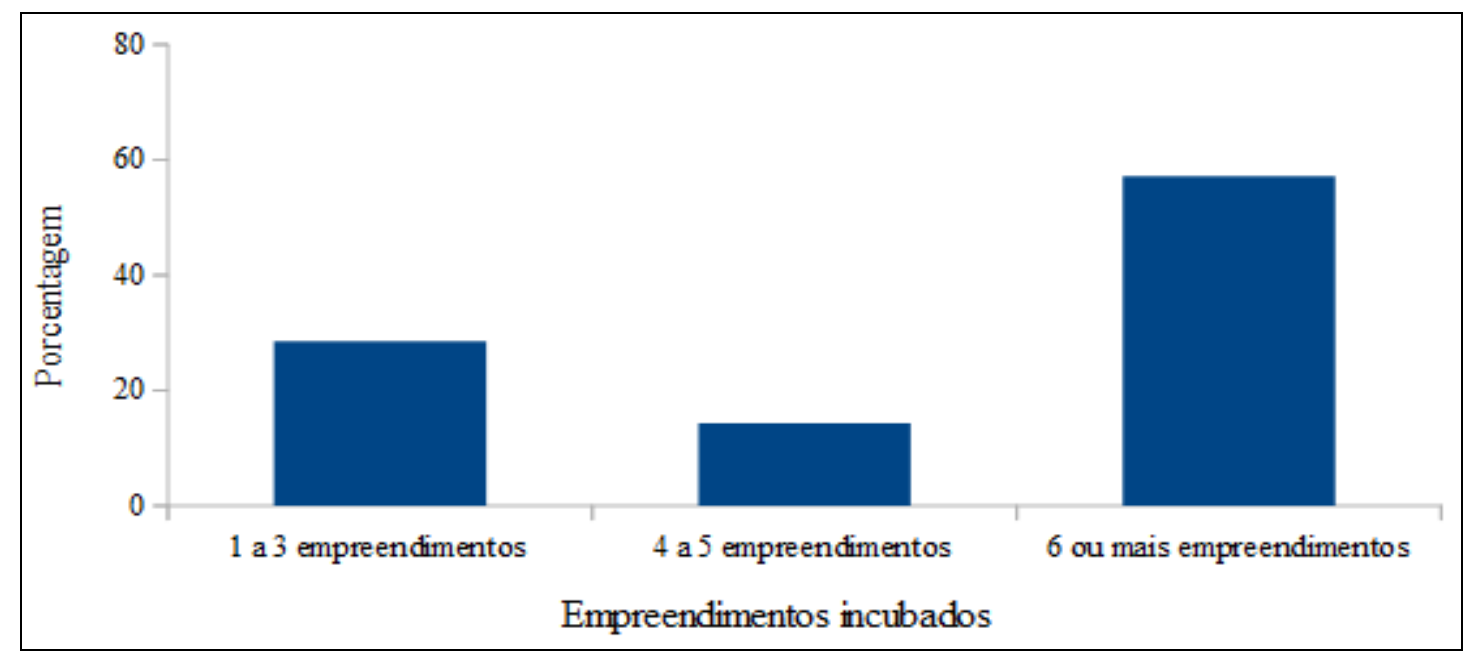

Figura 1 Quantidade de empreendimentos incubados nas incubadoras do RS.

Fonte: Elaborado pelos autores.

Quanto aos empreendimentos incubados nas ITCPs, eles atuam em distintas áreas, sendo a maioria destes atuantes na linha da Economia Solidária, Cooperativas e Agricultura Familiar (86\%), conforme pode ser visto na Figura 2. 


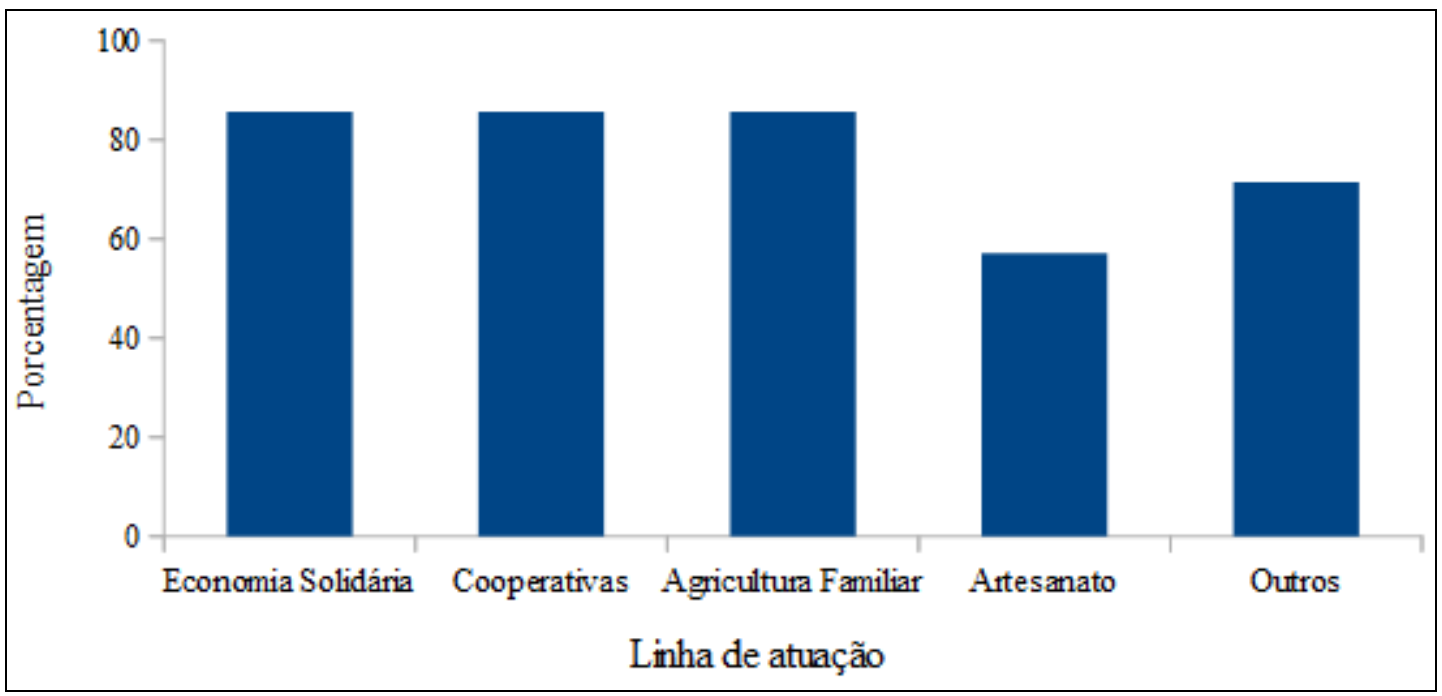

Figura 2 Linha de atuação dos empreendimentos incubados. Fonte: Elaborado pelos autores.

$\mathrm{Na}$ Figura 3, pode-se observar quais as principais dificuldades enfrentadas pelos empreendimentos no início da sua incubação. Observa-se que a maior dificuldade encontrada foi nos custos de financiamento, onde $100 \%$ das incubadoras questionadas afirmaram que seus empreendimentos tiveram muita dificuldade neste quesito. Outros pontos que também foi afirmado que houve muita dificuldade, foi no desenvolvimento de novos produtos $(83 \%)$ e na venda de produto $(67 \%)$.

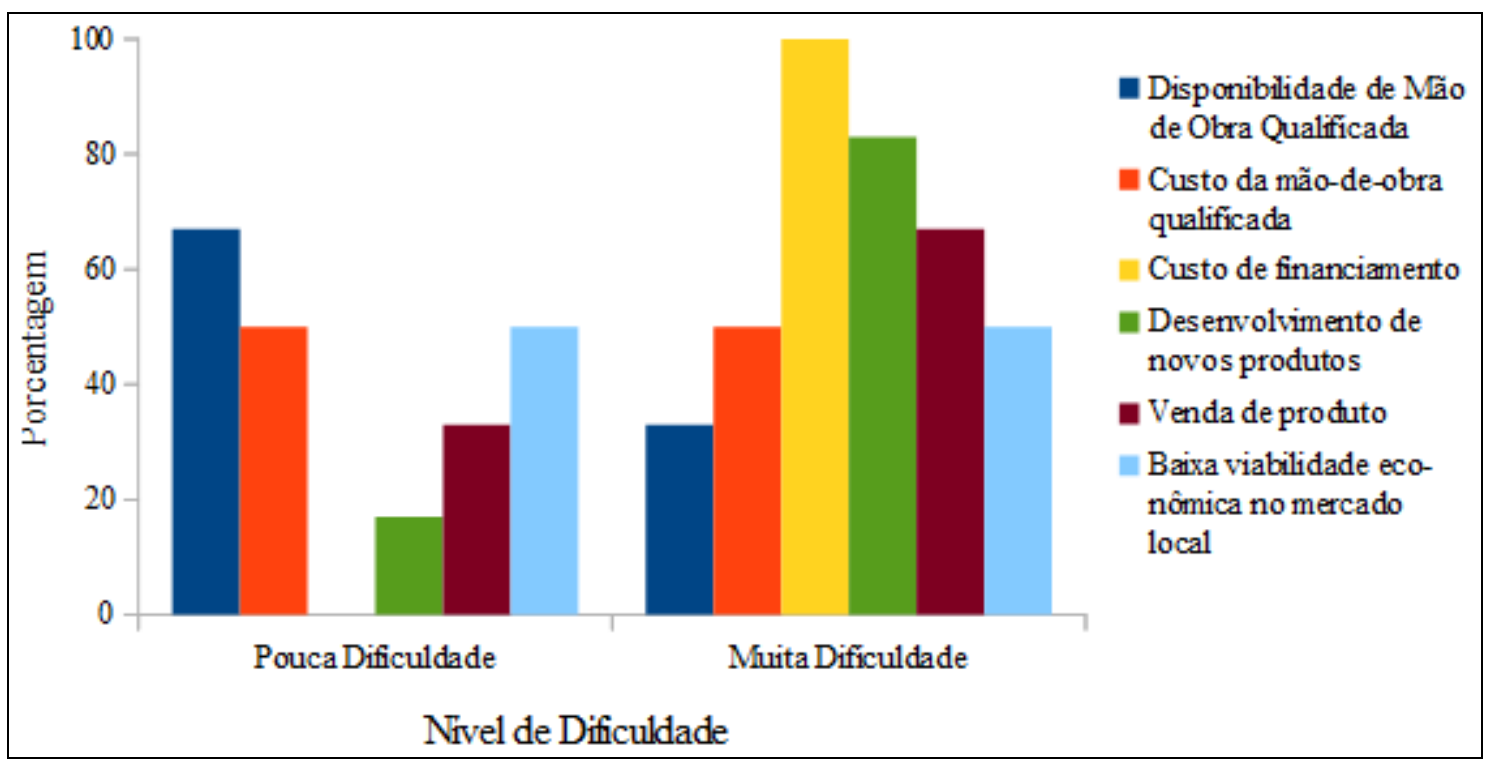

Figura 3 Nível de dificuldade apresentado pelos empreendimentos no início da incubação. Fonte: Elaborado pelos autores. 
Foi constatado com o questionário, que nem todos os empreendimentos incubados possuem legalização de suas atividades, sendo que 29\% das incubadoras afirmaram que os empreendimentos não possuem documentação e, $14 \%$ afirmaram que alguns empreendimentos incubados não estão regulares (Figura 4).

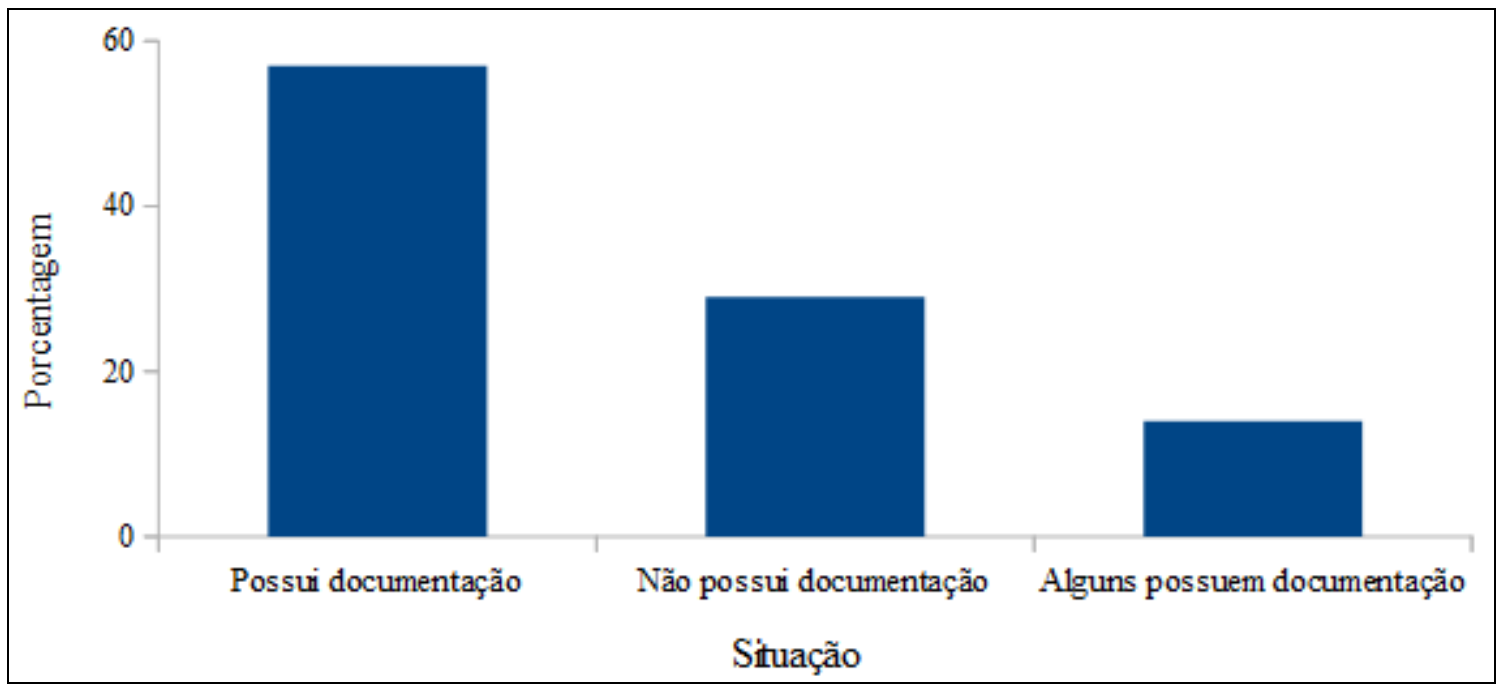

Figura 4 Legalização dos empreendimentos incubados. Fonte: Elaborado pelos autores.

Com o questionamento de como ocorre a comercialização dos produtos dos empreendimentos incubados, as ITCPs entrevistadas afirmaram que $71 \%$ dos empreendimentos fazem as vendas dentro do próprio empreendimento, $20 \%$ realizam vendas ativas onde vão pessoalmente oferecer seus produtos aos clientes e 57\% utilizam outros meios de comercialização, sendo que estes muitas vezes ocorrem simultaneamente (Figura 5).

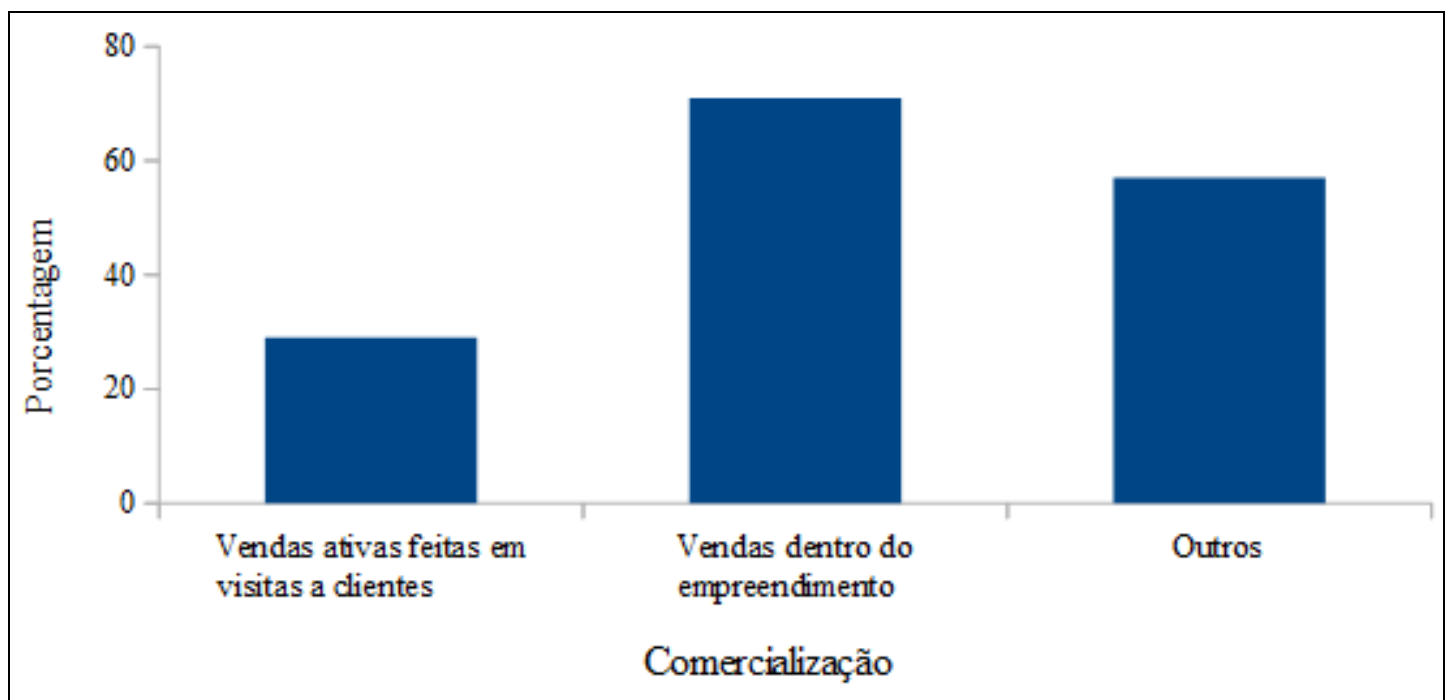

Figura 5 Como acontece a comercialização dos produtos dos empreendimentos incubados. Fonte: Elaborado pelos autores. 


\section{CONSIDERAÇÕES FINAIS}

A integração da extensão universitária, integrada com o ensino e pesquisa, possibilita significativas contribuições para os processos de ensino e aprendizagem, tanto para discentes como para os docentes envolvidos nesta atividade. A prática da extensão na Universidade é também um importante instrumento para esta cumprir a sua função social trazendo mudanças e promovendo melhorias na vida da população. Em vista disto, as ITCPs surgem como uma aplicabilidade da extensão universitária junto com o ensino e pesquisa, elas atuam na disseminação dos conhecimentos acadêmicos com os saberes populares promovendo assim, o desenvolvimento da região em que atuam.

A presente pesquisa busca identificar e avaliar como atuam estas ITCPs no Rio Grande do Sul, e partir dos resultados obtidos observou-se que esta limitou-se apenas na constatação dos dados, mostrando-se assim a necessidade de uma pesquisa mais aprofundada, principalmente dos dados expostos nas Figuras 3 e 4. Sugere-se que poderia ser realizada uma pesquisa qualitativa onde será possível identificar o porquê das dificuldades encontradas no início da incubação e qual a razão de nem todos os empreendimentos incubados possuírem documentação e legalização.

Os dados obtidos com os questionários, os quais serão disponibilizados para as incubadoras participantes da pesquisa, poderão ser de grande relevância para a Rede de ITCPs que está se organizando e discutindo seu estatuto. Com os resultados desta pesquisa, atrelados aos futuros dados de uma pesquisa qualitativa, poderá ser identificado mais facilmente quais os pontos a serem melhorados para favorecer a incubação de mais empreendimentos.

\section{REFERÊNCIAS BIBLIOGRÁFICAS}

\section{ANPROTEC. Sistema de Indicadores para Avaliação de Incubadoras e Empresas.} Brasília: ANPROTEC, 2003.

BEZERRA, A. F. A.; SILVA, W. S. C.; CARVALHO, Z. V. As Incubadoras Sociais e o Desenvolvimento Local: O que é e porque apoiar a iniciativa. In: SEMINÁRIO NACIONAL DE PARQUES TECNOLÓGICOS E INCUBADORAS DE EMPRESAS, 23., 2013, Recife, Anais... Recife: Anprotec, 2013.

DIAS, A. M. I. Pesquisa na Graduação e na Práxis Docente: Educação para emancipação humana. In: BEZERRA, T. S. A. M.; CAVALCANTE, L. M.; FRANCO, R. K. G.; SAMPAIO, L. M. P. A pesquisa na graduação: emancipação humana, práxis docente, trabalho e educação. Campina Grande: Realize Editora, 2012. 
DINIZ, E. H.; POZZEBON, M.; JAYO, M. Microcredit and correspondent banking in Brazil: what is missing? In: INTERNATIONAL WORKING CONFERENCE OF THE INTERNATIONAL FEDERATION FOR INFORMATION PROCESSING, 9., 2007, São Paulo. Anais... São Paulo: Workgroup 9.4, 2007.

ENGELMAN, R.; FRACASSO, E. M. Contribuição das incubadoras tecnológicas na internacionalização das empresas incubadas. Revista de Administração da Universidade de São Paulo, São Paulo, v.48, n.1, p.165-178, 2013.

FONSECA, S. A.; KRUGLIANSKAS, I. Avaliação do desempenho de incubadoras empresariais mistas: um estudo de caso no Estado de São Paulo, Brasil. In: CONFERÊNCIA LATINO-AMERICANA DE PARQUES TECNOLÓGICOS E INCUBADORAS DE EMPRESAS, 2000, Panamá. Anais... Panamá: IASP, 2000.

GUIMARÃES, G. Incubadoras Tecnológicas de Cooperativas Populares: contribuição para um modelo alternativo de geração de trabalho e renda. In: SINGER, P.; SOUZA, A. R. A economia solidária no Brasil - a autogestão como resposta ao desemprego. São Paulo: Contexto, 2000.

GURGEL, R. M. Extensão Universitária: Comunicação ou domesticação? São Paulo: Cortez, 1986.

IADH. Avaliação do Programa Nacional de Incubadoras Tecnológicas de Cooperativas e Empreendimentos Solidários - PRONINC. Recife: Secretaria Nacional de Economia Solidária, 2011.

IVATURY, G. Using technology to build inclusive financial systems. CGAP Focus Notes, n.32, 2006.

JAYO, M.; DINIZ, E. Um mapeamento descritivo dos modelos de gestão de redes de correspondentes bancários no Brasil. Revista de Administração da Universidade de São Paulo, São Paulo, v.48, n.3, p. 621-634, 2013.

JEZINE, E. As práticas curriculares e a extensão universitária. In: CONGRESSO BRASILEIRO DE EXTENSÃO UNIVERSITÁRIA, 2., 2004, Belo Horizonte. Anais... Belo Horizonte: UFRGS, 2004.

KUMAR, A.; NAIR, A.; PARSONS, A.; URDAPILLETA, E. Expanding bank outreach through retail partnerships: correspondent banking in Brazil. Working Paper n.85. Washington: World Bank, 2006.

LALKAKA, R.; BISHOP JR, J. L. Parques tecnológicos e incubadora de empresa: o potencial de sinergia. In: GUEDES, F.; FORMICA, P. A economia dos parques tecnológicos. Rio de Janeiro: Anprotec, 1997.

LYMAN, T.R.; IVATURY, G.; STASCHEN, S. Use of agentes in branchless banking for the poor: rewards, risks, and regulation. CGAP Focus Notes, n. 38, 2006. 
MEDEIROS, C. A. F. Comprometimento organizacional, características pessoais e performance no trabalho: um estudo dos padrões de comprometimento organizacional. Dissertação (Mestrado em Administração) - Universidade Federal do Rio Grande do Norte, Natal, 1997.

MELO NETO, J. F. Extensão universitária: bases ontológicas. MELO NETO, J. F. (Org.). Extensão universitária: diálogos populares. 1. ed. João Pessoa: Editora da Universidade Federal da Paraíba, 2002.

MORETTO NETO, L.; GARRIDO, P. O.; JUSTEN, C. E. Desenvolvendo o aprendizado em gestão social: proposta pedagógica de fomento às incubadoras sociais. Cad. EBAPE.BR, Rio de Janeiro, v. 9, n.3, art. 7, 2011.

MTE/SENAES. Secretaria Nacional de Economia Solidária. Disponível em $<$ http://portal.mte.gov.br/ecosolidaria/secretaria-nacional-de-economia-solidaria/> . Acesso em 17 de março de 2015.

NEVES, J. L. Pesquisa qualitativa: características, usos e possibilidades. Cadernos de Pesquisa em Administração, São Paulo, v.1, n.3, p.1-5, 1996.

NOGUEIRA, M. D. P. O Fórum de Pró-reitores de Extensão das Universidades Públicas Brasileiras: um ator social em construção. Interfaces - Revista de Extensão, v.1, n.1, p.3547, 2013.

RELATÓRIO DE TECNOLOGIA SOCIAL - RTS. 2007. 23p. Disponível em $<$ www.fbes.org.br/biblioteca22/relatorio_do_seminario_rts.doc $>$. Acesso em 01 de julho de 2014.

SERRANO, R. M. S. M. Conceitos de extensão universitária: um diálogo com Paulo Freire. Disponível em:

http://www.prac.ufpb.br/copac/extelar/atividades/discussao/artigos/conceitos_de extensao_un iversitaria.pdf $>$. Acesso em 08 de julho de 2015.

SILVA, A. C. L.; EIDELWEIN, K.; GAVIRAGHI, F. J.; BENEDETTO, E. S.; RITTER, C.; BALHEGO, L. F. M.; FERREIRA, G. G. Economia solidária no contexto das incubadoras sociais. In: SALÃO DA INICIAÇÃO CIENTÍFICA DA PUCRS, 5., 2009, Porto Alegre. Anais... Porto Alegre: PUCRS, 2009.

SOUZA, O. S. S. A extensão universitária e as universidades populares. Revista FACED, n.9, p.253-264, 2005.

SOUZA, M. C. A. F.; AZEVEDO, A.; OLIVEIRA, L. J. R.; BALDEON, N. T. Incubadora tecnológica de cooperativas - ITCP X Incubadora de base tecnológica - IEBT: Diferenças e semelhanças no processo de incubação. Revista Iboamericana de Ciência, Tecnologia, Sociedade e Inovação, n.6, 2003. 
TERENCE, A. C. F.; ESCRIVÃO FILHO, E. Abordagem quantitativa, qualitativa e a utilização da pesquisa-ação nos estudos organizacionais. In: ENCONTRO NACIONAL DA ENGENHARIA DA PRODUÇÃO, 26., 2006, Fortaleza. Anais... Fortaleza: ENEGEP, 2006.

UFPA. Universidade Federal do Pará. Incubadora Tecnológica de Cooperativas Populares: Formação e desenvolvimento de cooperativas populares como instrumento de geração de emprego e renda. Projeto de Extensão. Disponível em: < http://www.ufpa.br/cursoeconomia/extensao/projincubadora final.htm $>$. Acesso em $15 \mathrm{de}$ julho de 2015. 